\title{
Gestão de polo de apoio presencial no sistema Universidade Aberta do Brasil: construindo referenciais de qualidade
}

Edson Rosa Gomes da Silva - UFSC/(PGEGC) - edson@egc.ufsc.br Júlio César da Costa Ribas - UFSC (PGEGC) / IF-SC - julio@ifsc.edu.br Bruno César de Melo Moreira - UFSC (CPGA) - bcmmoreira@ yahoo.com.br Patrícia Battisti - UFSC/(PGEGC) - patriciabattisti@gmail.com Alice Theresinha Cybis Pereira - UFSC/(PGEGC) - acybis@ gmail.com

Resumo: O Polo de Apoio Presencial do sistema Universidade Aberta do Brasil - UAB é um elemento fundamental na estrutura de $\mathrm{EaD}$, constituindo-se numa extensão operacional da Instituição de Ensino Superior na cidade do estudante ou mais próxima dele e é onde acontecem os encontros presenciais, o acompanhamento e orientação para os estudos, as práticas laboratoriais e as avaliações presenciais. Visando garantir o pleno desenvolvimento das atividades dos cursos a distância e oferecer condições, serviços adequados, estes devem ser bem projetado e gerenciado. $\mathrm{O}$ presente artigo tem como objetivo elencar os diversos fatores estruturais e organizacionais essenciais à figura do coordenador do polo, com o objetivo de que este tenha ampla visão e domínio sobre sua gestão e garanta o funcionamento adequado do polo.

Palavras-chave: educação a distância, gestão de polos, polo de apoio presencial, Universidade Aberta do Brasil

The management of learners' support facilities: a challenge to the development of distance education in the system Brazilian Open University

\begin{abstract}
The learners' support facilities of the system Brazilian Open University $U A B$ represent a fundamental element in the distance education structure and constitute an operational extension of the Higher Education Institution in the student's town or in a town nearby. The facilities are the place where on-site classes are carried out, as well as attention and orientation to students, laboratory practices, and on-site evaluations. In order to provide for the adequate development of the activities of distance courses and to supply the necessary conditions and adequate services, the facilities should be well designed and managed. This study aims to list the structural and organizational factors which are essential to the role of coordinator of learners' support facilities, so that s/he has a wide vision and domain over her/his work and provides for the adequate operation of the facilities.
\end{abstract}

Keywords: distance education, learner-support facilities, management of learnersupport facilities. Brazilian Open University

\section{INTRODUÇÃO}

A educação a distância (EaD), no ensino de graduação, surge da necessidade de levar a educação a lugares remotos sem as tradicionais barreiras de tempo e espaço. Sem esta modalidade de ensino talvez nunca se chegasse a atingir uma série de pessoas ávidas por conhecimento. Apesar de seu surgimento remontar aos antigos gregos, só se consolidou como uma prática de ensino sistematizada no século XIX, e apenas no século seguinte chegou ao Brasil (SARAIVA, 1996). 
No Brasil, sua história inicia-se através do rádio, com a fundação da Rádio Sociedade do Rio de Janeiro, em 1923, e com os cursos por correspondência oferecidos pela Marinha, na década de 1930. Na década de 1940, surge o Instituto Universal Brasileiro, que propaga a educação a distância, ampliando a formação profissional de nível elementar e médio, através da utilização de material impresso (RODRIGUES, 1998). Rodrigues (1998) ressalta ainda a criação de inúmeros outros projetos de EaD nas décadas seguintes, como o Movimento de Educação de Base - MEB, criado em 1959, originário das escolas radiofônicas criadas pela Diocese de Natal, no Rio Grande do Norte; o Projeto Minerva, criado em 1970; e o projeto SACI, que atendia as quatro primeiras séries do primeiro grau e tinha o formato de uma telenovela. No final da década de 1970, numa parceria entre a Fundação Padre Anchieta (TV Cultura) e a Fundação Roberto Marinho, surge o Telecurso $2^{\circ}$ Grau. Este é um dos projetos de maior repercussão e continua ativo até hoje, preparando alunos do segundo grau para o exame de supletivo (RODRIGUES, 1998 apud PIMENTEL, 1995). Em 1995, nos mesmos moldes do Telecurso $2^{\circ}$ grau, foi lançado o Telecurso 2000 (RODRIGUES, 1998 apud PRETI, 1996). Rodrigues (1998) ainda menciona o programa "Um salto para o futuro", criado em 1991, por meio de parceria do Governo Federal, das Secretarias Estaduais de Educação e da Fundação Roquette Pinto, cujo objetivo é a formação de professores.

Entretanto, o ensino superior, através da universidade virtual, como se entende hoje, só surgiu a partir da metade da década de 1990 (Torres; Vianney, 2003). Como ressaltam os autores:

Até este período, a modalidade da Educação a Distância (EAD) era utilizada principalmente para ofertar cursos livres de iniciação profissionalizante, dentro do conceito de educação aberta e com os recursos do ensino por correspondência; e para ofertar cursos supletivos, focados na complementação de estudos nos níveis de Ensino Fundamental e de Ensino Médio, utilizando materiais impressos e aulas transmitidas por televisão, em programas de telecurso. Somente a partir de 1994, com a expansão da Internet junto às Instituições de Ensino Superior (IES), e com a publicação da Lei de Diretrizes e Bases para a Educação Nacional (LDB), em dezembro de 1996, que oficializa a EAD como modalidade válida e equivalente para todos os níveis de ensino, é que a universidade brasileira dedicase à pesquisa e oferta de cursos a distância com o uso de novas tecnologias. (TORRES; VIANNEY, 2003, p.2).

Mesmo com as mudanças na legislação que fortaleceram a modalidade de ensino a distância, o governo federal apresentou um programa abrangente de democratização do ensino superior no Brasil somente em 2006, quando foi instituído, através do Decreto $\mathrm{n}^{\circ} 5.800$ de 8 de junho de 2006, o sistema Universidade Aberta do Brasil (UAB).

A Universidade Aberta do Brasil é um sistema integrado por universidades públicas que oferece cursos de nível superior para camadas da população que têm dificuldade de acesso à formação universitária, por meio do uso da metodologia da educação a distância. (BRASIL, 2010).

Através da colaboração entre União (via universidades públicas) e entes federativos (através dos governos estaduais e municipais), criam-se centros de formação permanentes denominados polos de apoio presenciais, em localidades consideradas 
estratégicas. A UAB, com esses polos de ensino, permite, então, que se leve ensino superior de qualidade a lugares distantes, favorecendo a uma descentralização do ensino e a maior democratização e acesso (BRASIL, 2010).

O Polo UAB constitui, portanto, o "braço operacional" da instituição pública de ensino superior na cidade do estudante (ou na mais próxima dele), onde acontecem os encontros presenciais, o acompanhamento e orientação para os estudos, as práticas laboratoriais e as avaliações presenciais.

Entretanto, para garantir efetivamente o pleno desenvolvimento das atividades dos cursos a distância e oferecer condições e serviços adequados e suficientes para atender os professores e estudantes em suas expectativas, demandas e necessidades, $\mathrm{o}$ polo de Apoio presencial precisa ser bem projetado. As instalações físicas, a infraestrutura tecnológica e de recursos humanos, desta forma, mostram-se essenciais para contribuir na qualidade do ensino.

No entanto, a gestão de polos de apoio presenciais tem constituído um problema, devido à carência de encaminhamentos adequados para gerenciamento $\mathrm{e}$ operacionalização destes ambientes. Apesar das exigências do governo federal para a implantação de polos de apoio presenciais, não são contemplados diversos aspectos relacionados à sua gestão que se mostram vitais para o bom funcionamento e perenidade do polo.

Neste cenário, surge nossa pergunta de pesquisa: Quais são os principais fatores internos, externos, estruturais, organizacionais e metodológicos que afetam a qualidade da gestão nos polos?

Para responder a pergunta que motiva este trabalho, o presente estudo tem como objetivo apresentar os fatores internos, externos, estruturais, organizacionais, metodológicos essenciais à figura do coordenador do polo, a fim de que este tenha um amplo domínio sobre sua gestão.

\section{METODOLOGIA ADOTADA}

Este artigo procura racionalizar a pesquisa sobre a gestão de polo de apoio presencial por uma visão empírica. Para alcançar este objetivo, utiliza-se apoio da pesquisa exploratória, que mescla a pesquisa documental com a pesquisa bibliográfica. Procurouse suporte na bibliografia correspondente à área de interesse, ou seja, artigos e livros, que dessem sustentação às proposições para uma gestão eficiente dos polos.

Entretanto também se focou na legislação, normativas e diretrizes vigentes para a área de ensino a distância. Verificaram-se as características essenciais que devem compor o repertório de conhecimentos dos coordenadores de polos.

Como suporte empírico, aproveitou-se a experiência dos profissionais envolvidos na produção do artigo, pois estes têm ativa experiência com a educação a distância, bem como contatos diversos com tutores, professores, monitores e coordenadores de polos. Assim, entendem as necessidades e procuram apresentar um olhar crítico, mas ponderado, sobre as dificuldades encontradas na direção dos trabalhos em polos de apoio presenciais.

Com este suporte, o artigo procura sugerir com base na pesquisa exploratória e em evidência empírica, as nuances, por meio de uma exposição ponderada dos entendimentos acerca do assunto em pauta.

\section{O POLO DE APOIO PRESENCIAL}

Os polos de apoio presenciais são as unidades operacionais para o desenvolvimento descentralizado de atividades pedagógicas e administrativas relativas aos cursos e 
programas ofertados a distância pelas instituições públicas de ensino superior no âmbito do Sistema UAB. Mantidos por municípios ou governos de Estado, os polos oferecem a infraestrutura física, tecnológica e pedagógica para que os alunos possam acompanhar os cursos a distância (POLO, 2010).

Um polo de apoio presencial também pode ser entendido como "local de encontro" onde acontecem os momentos presenciais, o acompanhamento e a orientação para os estudos, as práticas laboratoriais e as avaliações presenciais. O objetivo dos polos é oferecer o espaço físico de apoio presencial aos alunos da sua região, mantendo as instalações físicas necessárias para atender aos alunos em questões tecnológicas, de laboratório, de biblioteca, entre outras.

A questão da gestão de um polo de apoio presencial está diretamente ligada a sua estrutura, formalmente definida e disciplinada pelo Sistema Universidade Aberta do Brasil. O êxito do Sistema, indubitavelmente, depende de seu bom funcionamento, que garanta uma estrutura administrativa e pedagógica adequada para atendimento e, fundamentalmente, gestores capacitados.

\subsection{A estrutura de um polo de apoio presencial}

A literatura apresenta uma proposta de estrutura mínima no que tange a ambiente, mobiliários e equipamentos de um polo de apoio presencial, como forma de nortear as ações dos seus mantenedores, estados e/ou municípios, além de oferecer uma base de estimativa para os investimentos que deverão ser feitos na adequação de um prédio público, para que o mesmo venha a abrigar um polo de apoio presencial da UAB. Um polo deverá ter, no mínimo, os seguintes ambientes: salas para secretaria acadêmica, coordenação de polo, tutores presenciais, professores, sala de aula presencial, laboratório de informática e biblioteca. Referidos ambientes devem ser dotados de mobiliários e equipamentos compatíveis com cada atividade. Computadores, equipamentos para videoconferência, impressora, linha telefônica e acesso dedicado a Internet em todos os ambientes são requisitos indispensáveis para o funcionamento do polo (ESTRUTURA UAB/CAPES, 2010).

No tocante aos recursos humanos mínimos em um Polo UAB, são recomendados os seguintes atores: Coordenador de Polo (responsável pela parte administrativa e pela gestão acadêmica); tutor presencial; técnico de laboratório pedagógico, quando for o caso; técnico em informática; bibliotecária e auxiliar para a secretaria (ESTRUTURA UAB/CAPES, 2010).

A estrutura proposta configura-se como um balizador. A aquisição de equipamentos específicos depende dos cursos a serem ofertados e de orientações das instituições de ensino superior - IES - que oferecem esses cursos no polo. Cursos como biologia, física, química e matemática, por exemplo, exigem um investimento adicional em laboratórios. O quantitativo para a aquisição de alguns equipamentos e mobiliário dependerá do número de cursos e alunos que o polo pretende abrigar.

No que concerne aos recursos humanos, especificamente ao coordenador de polo, este é selecionado pelas instituições de ensino superior - IES - que ofertam cursos no polo, a partir de uma lista tríplice encaminhada pelo mantenedor para as coordenações UAB das IES. O profissional indicado precisa atender a requisitos mínimos, a saber: formação acadêmica superior e experiência docente na educação básica ou superior de no mínimo três anos. A UAB oferece bolsas aos coordenadores e aos tutores presenciais. A remuneração dos demais fica a cargo do mantenedor do polo.

3.2 Atribuições de um coordenador de polo 
As atribuições do coordenador do polo são disciplinadas pelo Anexo I da Resolução CD/FNDE $\mathrm{N}^{\circ} 26$, de 5 de junho de 2009, que estabelece orientações e diretrizes para pagamento das bolsas do Sistema Universidade Aberta do Brasil. (Brasil, 2009), conforme segue:

- Acompanhar e coordenar as atividades docentes, discentes e administrativas do polo de apoio presencial;

- Garantir às atividades da UAB a prioridade de uso da infraestrutura do polo de apoio presencial;

- Participar das atividades de capacitação e atualização;

- Elaborar e encaminhar à DED/CAPES relatório semestral das atividades realizadas no polo, ou quando solicitado;

- Elaborar e encaminhar à coordenação do curso relatório de frequência e desempenho dos tutores e técnicos atuantes no polo;

- Acompanhar as atividades de ensino, presenciais e a distância;

- Acompanhar e gerenciar o recebimento de materiais no polo e a entrega dos materiais didáticos aos alunos;

- Zelar pela a infraestrutura do polo;

- Relatar problemas enfrentados pelos alunos ao coordenador do curso;

- Articular, junto às IPES presentes no polo de apoio presencial, a distribuição e o uso das instalações do polo para a realização das atividades dos diversos cursos;

- Organizar, junto com as IPES presentes no polo, calendário acadêmico e administrativo que regulamente as atividades dos alunos naquelas instalações;

- Articular-se com o mantenedor do polo com o objetivo de prover as necessidades materiais, de pessoal e de ampliação do polo;

- Receber e prestar informações aos avaliadores externos do MEC.

\section{A GESTÃO DO POLO DE APOIO PRESENCIAL EM CONTEXTO}

Uma maneira eficiente de realizar a capacitação do coordenador de polo é utilizar um ambiente virtual de aprendizagem - AVA. Através do uso da plataforma, é possível fazer com que os coordenadores de polos possam interagir, trocando experiências, aprendendo novas maneiras de gerir um polo para que assim possam utilizá-lo de maneira eficiente, buscando a máxima produtividade. Outro fator importante é a padronização dos conhecimentos adquiridos, pois os coordenadores terão um arcabouço teórico similar, que conduzirá suas administrações nos polos. Neste processo a bagagem intelectual dos gestores, aliada à estrutura pedagógica das disciplinas da capacitação e a interação em grupo, trará um grande diferencial na gestão dos polos.

Aprender é planejar, é desenvolver ações, é receber, selecionar e enviar informações, é estabelecer conexões, é refletir sobre o processo em desenvolvimento, em conjunto com os pares, é desenvolver a interaprendizagem, a competência de resolver problemas em grupo e a autonomia em relação à busca, ao fazer e ao compreender. As informações são selecionadas, organizadas e contextualizadas segundo as expectativas do grupo, permitindo estabelecer múltiplas e mútuas relações, retroações e recursões, atribuindo-lhes um novo sentido que ultrapassa a compreensão individual (ALMEIDA, 2003).

Criar mecanismos capazes de propiciar o planejamento, organização e capacitação da direção e de controle das atividades desenvolvidas, segundo Oliveira 
(2007), é elemento basilar para que as organizações atinjam seus objetivos. Desenvolver programas e projetos, contemplando o resultado do planejamento elaborado pelas organizações, torna-se elementar, ou seja, uma atividade quase que trivial, embora desenvolvida com deficiências por muitas organizações, principalmente com relação ao desdobramento dos objetivos do planejamento em questão.

$\mathrm{Na}$ implantação e operacionalização de um curso superior, principalmente na modalidade a distância, diversos aspectos devem ser observados visando o atendimento da demanda com qualidade aceitável. Na modalidade a distância, um polo de apoio presencial necessita de suporte administrativo e pedagógico para lograr êxito em suas ações e atingir a excelência almejada dentro de um processo de ensino aprendizagem, que é o foco pretendido.

Dentro desse contexto, é possível estabelecer as seguintes necessidades de capacitação específicas, visando a formação de um coordenador de polo munido de ferramentas e elementos imprescindíveis à boa administração. Assim, constitui questão estratégica de fundamental importância dentro de um polo o domínio e emprego das técnicas relacionadas com:

- Gestão estratégica;

- Gestão de projetos;

- Gestão da infraestrutura;

- Gestão de equipe;

- Gestão de processos.

Contudo, os candidatos a gestores dos polos devem ter algumas características inerentes ao cargo pretendido como já mencionado, mas devem passar por um processo de homogeneização de saberes.

A capacitação prevê cinco etapas, cada qual abordada de acordo com suas especificidades pretendidas, como se pode observar:

\subsection{Gestão estratégica}

A noção de gestão estratégica vem evoluindo ao longo do tempo. Segundo Tavares (1991), a gestão estratégica pode ser conceituada como o planejamento estratégico aliado à tomada de decisão em todos os níveis da organização. Já Fischmann e Almeida (1991, p. 26) vêem gestão estratégica como a capacitação dos agentes da organização em dirigir seus rumos de forma a permitir que as decisões administrativas e operacionais estejam de acordo com as decisões estratégicas. E Wright et al. (2000) conceituam-na como congregação de esforços como o propósito de alcançar a missão e os objetivos da organização frente aos seus ambientes (externo e interno) e à administração dos estágios de formulação, implementação e controle da estratégia. A partir dessas conceituações pode-se perceber que a capacitação de um coordenador de polo tem pressupostos que visam alcançar uma uniformidade de ações e resultados no polo.

Desta forma, não adianta haver polos estrategicamente bem dirigidos e outros lançados a própria sorte. A gestão de um polo deve seguir o que preceitua a gestão estratégica, ou seja, um "processo contínuo e iterativo que visa manter uma organização, como um conjunto apropriadamente integrado ao seu ambiente" e aos propósitos de sua criação (CERTO e PETER, 1993, p. 6). Sem o domínio dessa etapa, o coordenador pode conduzir o polo por caminhos tortuosos e causar transtornos aos professores, tutores e coordenação geral dos cursos e dos polos, tornando assim insustentável sua permanência na condução do polo. 


\subsection{Gestão de projetos}

Um projeto é um empreendimento que tem começo, meio e fim e é cercado de meandros ao longo de sua consecução. O Project Management Institute - PMI® (2004) dispõe uma definição de gerenciamento de projetos que se preocupa com a aplicação prática de gerenciar os projetos. Esta definição é relacionada com a aplicação de conhecimentos, habilidades, ferramentas e técnicas nas várias atividades que são realizadas para alcançar as necessidades e as expectativas do empreendimento, de forma a atingir um equilíbrio no que se refere a escopo, prazo, custo, riscos, qualidade e outras metas das áreas de conhecimento. Um coordenador de polo pode e deve utilizar o conhecimento de gestão de projeto para controlar os processos administrativos e pedagógicos nos polos.

Os conhecimentos adquiridos dentro deste ferramental, disponibilizado aos coordenadores de polos, pode ajudar no desenvolvimento de projeto no polo, como também no entendimento de projetos capilarizados da coordenação geral de polos.

\subsection{Gestão da infraestrutura}

A gestão de infraestrutura é um ponto de fundamental importância dentro da administração de um polo. O alinhamento da comunicação para resolver problemas de várias naturezas passa pelo conhecimento da linguagem utilizada no processo de comunicação. Muitos gestores de empresas não estão alinhados com seus setores de tecnologia em boa parte das empresas de serviço.

Brodbeck e Hoppen (2000) destacam o interesse por estudos sobre o alinhamento estratégico de tecnologia de informação (TI) em organizações e aponta que esta preocupação tem aumentado consideravelmente. Isso é visto tanto no meio acadêmico como no meio empresarial. Pela heterogeneidade dos coordenadores de polos, pode-se extrapolar este entendimento para a área de ensino a distância.

O site da Coordenadoria de Ensino a Distância da Universidade Federal de Santa Catarina (Cead, 2010), por exemplo, apresenta um entendimento do que seja a gestão de infraestrutura e aponta que "trata do mapeamento e organização das condições básicas existentes para potencializar o uso compartilhado e propor alternativas para se buscar as condições necessárias na instituição e nos polos". Assim, quando se fala da gestão da infraestrutura nos polos, está-se preocupado em manter disponíveis os sistemas aos usuários, sejam eles alunos, tutores, professores ou coordenadores. O serviço de gestão de infraestrutura tem que assegurar aos usuários todos os recursos de tecnologia (sistemas e aplicativos) e que estes estejam disponíveis e em bom funcionamento. Os usuários devem poder usufruir dos recursos de qualquer local, dia e horário, ou seja, de todo potencial do parque tecnológico do polo, para que assim possam alcançar a plena satisfação no desempenho de suas atividades.

\subsection{Gestão da equipe}

Trabalhar dentro da perspectiva da necessidade de criação de uma boa equipe de trabalho é fundamental para que se consigam atingir os resultados esperados. $\mathrm{O}$ trabalho em equipe é imprescindível, já que bons resultados dificilmente nascem de ações individuais.

Questões em torno da construção de uma boa equipe de trabalho são inúmeras, como apresentam Bejarano e Pilatti (2007, p. 18), que destacam, entre outras: "a falta de esforço e apoio por parte das empresas na construção das equipes [...], falta de objetivos 
definidos, inclinação individualista [...] e métodos de seleção inadequados". As dificuldades são muitas e cabe ao gestor ter os mecanismos certos para conseguir formar uma boa equipe e utilizar as técnicas adequadas para conduzir sua equipe para o sucesso.

O coordenador de polo deve ter uma boa equipe para desenvolver seus projetos e conduzir os cursos com a excelência que se espera. Assim, selecionar adequadamente uma equipe e conseguir tirar o máximo dela é fundamental para um polo de educação a distância. Este conhecimento deve estar no rol de disciplinas e fazer parte da capacitação dos coordenadores de polos.

\subsection{Gestão de processos}

Quando se fala em gestão de processos ou gestão por processos se verifica que há muitas varáveis envolvidas dentro das ações para que se consigam atingir os resultados almejados. Estas variáveis afetam no desencadeamento das tarefas e ações e podem gerar, muitas vezes, alterações nos resultados pretendidos.

Processos são conjuntos de ações sistemáticas, baseadas em fatos, tarefas, dados e ações, que permitem manter estável a rotina. Desta forma, entende-se o processo como uma série de rotinas que produzem um resultado determinado. $\mathrm{O}$ domínio pelos coordenadores dos processos que acontecem nos polos de apoio presenciais fará a diferença na resolução de problemas que ocorrerem e facilitará sua resolução.

A excelência de gestão de polos de apoio presencial é fundamental para um desenvolvimento profícuo do trabalho de mediação do ensino e aprendizagem. Como forma de gerir os polos, seus gestores devem estar munidos de capacidades intelectuais e de posse de ferramentas que ajudem a administrar o polo eficientemente.

\section{CONCLUSÕES}

A partir do que foi discutido no início do artigo, pode-se perceber que, ao se interiorizar e expandir os cursos via modalidade a distância, a sociedade ganha, pois se está contribuindo para a elevação de nível de escolaridade da população, principalmente devido ao fato de a EaD transpor barreiras de tempo e espaço. Este processo propicia às pessoas maior capital intelectual e possibilita sua inserção em mercado de trabalho mais especializado.

Deve-se trabalhar constantemente para disponibilizar um serviço de excelência no ensino, seja ele presencial ou a distância, pois segundo a legislação não pode haver diferença entre as modalidades de ensino. Sabe-se que a estrutura de suporte do ensino presencial é mais bem consolidada nos locais onde ocorre a interação com os alunos. Dentro desta perspectiva, verifica-se a necessidade de se ter um polo de apoio presencial bem estruturado para dar suporte adequado a estudantes, professores, tutores e técnicos. Assim, propicia-se que funcione melhor o sistema da Universidade Aberta do Brasil, que tem nos polos uma parte importante de seu funcionamento. Nesse contexto, a liderança do polo, ou seja, o gestor necessita de conhecimento para desenvolver um bom trabalho na condução administrativa e pedagógica dos polos.

Este artigo procurou apresentar uma linha central para capacitação destes profissionais, que exercerão a função de gestor nos polos de apoio presencial. Não se pretendeu ser exaustivo na apresentação de disciplinas, mas sim elencar conceitos fundamentais para emprego na condução e administração dos polos e para que os gestores tenham conhecimentos homogêneos para resolução de problemas. Assim, foram destacadas algumas áreas para suporte à gestão, como, por exemplo, gestão estratégica, gestão de projetos, gestão da infraestrutura, gestão de equipe e gestão de 
processos. Com os conhecimentos advindos da experiência prática dos autores, percebese que a resolução de boa parte dos problemas encontrados nos polos passa por alguma das áreas apresentadas.

Como trabalho futuro, pretende-se dar suporte científico às colocações acima formuladas, com base em uma avaliação conjunta com os coordenadores de polos, verificando quantitativamente o domínio acerca dos conhecimentos propostos e a necessidade de entendimento dos conceitos apresentados.

\section{REFERÊNCIAS BIBLIOGRÁFICAS}

ALMEIDA, M. E. B. Educação a distância na internet: abordagens e contribuições dos ambientes digitais de aprendizagem. 2003, vol.29, n.2, pp. 327-340. ISSN 15179702.

BEJARANO, V. C; PILATTI, L. A. Elementos Externos Essenciais à Implementação de Equipes: estudo de caso. 2007. Disponível em:

<http://www.portaleducacao.com.br/arquivos/artigos/1236951867_Gest\%E3o\%20de\%2 0Equipes.pdf $>$. Acesso em: 13 jul. 2010.

BRASIL. UAB/CAPES. Sobre a UAB: O que é. Disponível em: http://www.uab.capes.gov.br. Acesso em: 5 jul. 2010.

BRASIL. UAB/CAPES. Resolução CD/FNDE N² 26, de 5 DE junho de 2009.

Estabelece orientações e diretrizes para pagamento das bolsas do Sistema Universidade Aberta do Brasil. Diário Oficial da República Federativa do Brasil, Brasília, 8 jun. 2009. Seção 1, p.12.

BRODBECK, A; HOPPEN, N. Modelo de alinhamento estratégico para implementação dos planos de negócio e de tecnologia de informação. Anais do XXIV Encontro Nacional da ANPAD, Florianópolis. 2000.

CEaD UFSC. Gestão de Infraestrutura. Disponível em:

http://www.ead.ufsc.br/cead/gestao-de-infra-estrutura/>, Acesso em: 15 jul. 2010.

CERTO, S; PETER, J. P. Administração estratégica. São Paulo: Makron Books. 1993.

ESTRUTURA UAB/CAPES. Modelo de polo de apoio presencial. Disponível em: http://www.uab.capes.gov.br/index.php?option=com_content\&view=article\&id=17:mod elo-de-polo-de-apoio-presencial-\&catid=10:polos\&Itemid=31. Acesso em: 6 jul. 2010.

FISCHMANN, A; ALMEIDA, M. I. R. Planejamento estratégico na prática. $2^{\mathrm{a}} \mathrm{ed}$. São Paulo: Atlas, 1991.

LÉVY, P. As tecnologias da inteligência: o futuro do pensamento na era da informática. São Paulo: Editora 34, 1996.

OLIVEIRA, D. P. R. Planejamento estratégico. São Paulo: Atlas, 2007.

POLO UAB/CAPES. O que é um polo de apoio presencial. Disponível em: http://www.uab.capes.gov.br/index.php?option=com_content\&view=article\&id=16:0que-e-um-polo-de-apoio-presencial\&catid=10:polos\&Itemid=30, Acesso em: 6 jul. 2010.

PMI®. A guide to the project management body of knowledge (PMBOK® Guide), 3rd ed. Project Management Institute, 2004.

RODRIGUES, R. S. Modelo de avaliação para cursos no ensino a distância: estrutura, aplicação e avaliação. Dissertação (Mestrado) - Departamento de Programa 
de Pós-graduação em Engenharia de Produção, UFSC, Florianópolis, 1998.

SARAIVA, T. Educação a distância no Brasil: lições da história. Em Aberto, Brasília, ano 16, n. 70, abr./jun, 1996, p. 17-27.

TAVARES, M. C. Planejamento estratégico: a opção entre sucesso e fracasso empresarial. São Paulo: Harba, 1991.

TORRES, P; VIANNEY, J. Os paradoxos do ensino superior a distância no Brasil. Tubarão, SC: Editora Unisul, 2003.

WRIGHT, P.; KROLL, M. J; PARNELL, J. Administração estratégica: conceitos. São Paulo: Atlas, 2000. 